\title{
Burnout in the age of COVID-19
}

\section{John Launer}

The theme of this issue of the Postgraduate Medical Journal is burnout. As Professor Bernard Cheung makes clear in his editorial $^{1}$ physician burnout is not due to failings on the part of any individual. It is far more a consequence of social, cultural and technological pressures that affect the profession as a whole. Few young people applying for medical school can imagine what most medical careers nowadays are actually like: a decade or more in further studies, working hours that may be twice as long as their former school friends, possibly earning half or a quarter as much as some comparable professions, and in work settings where bureaucracy, technology and managerialism may trump vocation, professionalism or prestige. In effect, the conditions for burnout are set early on.

The doctors who manage to transcend these challenges appear mainly to be those who are imbued with a particular passion. According to Tait Shanafelt and his team of leading researchers on burnout at Stanford University, attempts to deal with the problem should therefore aim at "high professional fulfilment, rather then just burnout mitigation"2 Some doctors achieve such fulfilment as academic researchers, competent administrators, medical politicians, or leaders of institutions. An increasing number choose to divide their energies between medicine and their families, or have an absorbing outside interest like sport or the arts. At some point in their lives, they have accepted that medicine for them is just a job like any other, and does not require martyrdom more than being in any other profession. Although some doctors do continue to be fired with enthusiasm as full time clinicians until the day they retire, the assumption that all doctoring is like this is misplaced. We need to protect younger doctors from expecting they will all achieve this ideal.

Without such measures, few are shielded from the risk of burnout. I have certainly experienced this myself. In midcareer I was a general practitioner (GP.) seeing forty or more patients a day, with very limited time to see each patient, and

Associate Editor, Postgraduate Medical Journal, London, UK

Correspondence to Dr John Launer, London, UK; johnlauner@aol.com having to deal with increasing demands on primary care. I remember the gloom and dread that I experienced on some mornings as I turned the key to let myself in at the staff door of our clinic. I can also recall the surges of anger I felt at any additional demand that came my way during the course of the day: an extra unscheduled patient, a phone call requesting a home visit when I thought I had none to do, or a night call to see someone ill or dying. These reflexes had nothing to do with whether the patients' needs were "appropriate" or not. They were an embodiment of my own need to escape from a system that I felt was abusive of doctors and patients alike. In time I emerged from this state with the help of my wife, GP partners, therapy, additional training and an evolution in my career to being not just a clinician but an educator and writer. But the experience protected me from the illusion that anyone is immune from burnout. More of our colleagues than we will ever know function on the edge of these feelings, however robust and successful they may seem on the outside.

\section{RESILIENCE AND OUTRAGE}

Currently, it is impossible to reflect on burnout without thinking about the potential impact of the COVID-19 pandemic. Possibly the crisis will heighten people's sense of vocation, transforming the personal and technological relationships we have with patients. Alternatively, the distress and exhaustion of everyday clinical work during the pandemic, along with the loss of colleagues and loved ones, may lead many doctors to become disillusioned or to despair. Until the pandemic is over, it will be hard to know what its lasting effects on physician burnout will be.

In the last few weeks, for example, the profession in the UK has adapted with extraordinary speed and resilience to the use of remote technology for clinical encounters, supervision, education and management. I have admired how trainees have moved without reservation into the most exposed specialties like emergency medicine and critical care. Services for supporting doctors through coaching, counselling and mentoring have sprung up in days, when previously it might have taken years to organise these. I have also noticed how the profession has ratcheted up the pace with which vital information has been disseminated, both nationally and worldwide, so patients get the best management at each stage of coronavirus infection, from triage through to mechanical ventilation or palliative care. Paradoxically, all these developments may serve to inspire doctors who may otherwise have been flagging.

The other side of this is also tragically obvious. Doctors and healthcare staff are dying. More deaths will no doubt follow. Against a background of economic austerity, and fragmentation of our health service, the response of the UK government has been widely judged to be tardy and inadequate. ${ }^{3}$ From the outset it chose to ignore WHO guidance about preparing for testing, quarantine, personal protective equipment and the timing of lockdown. There is a now sense of life-threatening vulnerability among our healthcare professions. It remains to be seen if people's altruism will continue to overcome the growing outrage that accompanies this. Doctors, nurses, ward assistants and cleaners do not expect to die as part of their calling, as members of the armed forces do.

\section{POLITICAL RESPONSE}

Much may depend on the broader political response among governments. Until the pandemic started, the trajectory across much of the globe appeared to be one of increasing nationalism, along with the relentless siphoning of wealth to a tiny number of corporations and individuals. None of this was good for global health, nor for the well-being of the health professions. It is just possible that the COVID-19 pandemic may exert a sobering effect on politicians or, more likely, a radicalising influence on populations, and thus reverse this trajectory - for example by bringing about more equitable approaches to public health, including a recognition of the need to sustain physician well-being. As always, the way that doctors think, feel and act will depend not so much on our own will but on the world around us.

\section{Twitter John Launer @JohnLauner}

Funding The authors have not declared a specific grant for this research from any funding agency in the public, commercial or not-for-profit sectors.

Competing interests None declared.

Patient consent for publication Not required.

Provenance and peer review Not commissioned; internally peer reviewed.

(C) Author(s) (or their employer(s)) 2020. No commercial re-use. See rights and permissions. Published by BMJ. 


\section{On reflection}

\section{(A) Check for updates}

To cite Launer J. Postgrad Med J 2020;96:367-368.

Postgrad Med J 2020;96:367-368 doi:10.1136/postgradmedj-2020-137980

\section{REFERENCES}

1 Cheung B. Burnout - a burning issue. Postgrad Med J 2020;96:309.
2 Shanafelt T, Trockel M, Ripp J, et al. Building a program on well-being: key design considerations to meet the unique needs of each organization. Acad Med 2019:94:156-61.

3 Horton R. Offline: COVID-19-a reckoning. Lancet 2020;395:935. 